\title{
Estudo de caso em pesquisa educacional
}

\section{Case study in research educational}

\section{Estudio de caso en investigación educativa}

\author{
Francy Sousa Rabelo \\ Universidade Estadual do Ceará \\ Universidade Federal do Maranhão (Brasil) \\ Maria Socorro Lucena Lima \\ Universidade Estadual do Ceará (Brasil)
}

ANDRÉ, Marli Eliza Dalmazo Afonso de. Estudo de caso em pesquisa e avaliação educacional. 3. ed. Brasília: Líber livro, 2008. 70p.

O livro Estudo de Caso em Pesquisa e Avaliação Educacional traz o conceito de estudo de caso como sendo um estudo em profundidade de um fenômeno educacional, com ênfase na sua singularidade, levando em conta os princípios da etnografia.

O interesse da autora pelo tema se deu a partir da sua participação na disciplina "Estudo de Caso em Currículo", na Universidade de Illinois, em Urbana-Campaing, nos Estados unidos, ministrada pelo professor Robert Stake. André afirma que acompanhou o movimento de crítica e fortalecimento do estudo de caso no contexto da pesquisa norte-americana.

A primeira parte do livro apresenta um percurso histórico sobre a utilização do estudo de caso no âmbito das diferentes áreas das ciências e aponta as críticas que recebeu no seu surgimento no contexto educacional nas décadas de 1960 e 1970. O estudo de caso foi caracterizado como uma metodologia científica muito restrita para a realização da pesquisa, considerado uma descrição de uma unidade, uma visão exploratória ou preparatória para um trabalho posterior de pesquisa.

André dialoga com vários autores internacionais para explicitar os diversos tipos de estudo de casos. Entre os trabalhos de pesquisa consultados, apresenta a classificação de Stake com o estudo de caso intrínseco (tem-se um interesse intrínseco no caso particular); estudo de caso instrumental (uma questão a elucidar de um caso particular) e o estudo de caso coletivo Inão se concentra em um só caso, mas em vários com finalidade intrínseca 
ou instrumental). Apresenta, ainda, a tipologia definida por Stenhouse com caráter etnográfico (estudo em profundidade pela observação participante e entrevista), avaliativo (estudo para auxiliar no julgamento de um mérito ou valor de políticas, programas ou instituições), educacional (busca compreender uma ação educativa) e de ação (por meio de feedback, o caso-ação contribui para guiar a revisão de uma ação). André faz a defesa do "estudo de caso etnográfico", apresentado na parte seguinte do livro.

Assim, enfatiza o princípio básico da etnografia para o estudo de caso, que é a relativização, cuja ação se faz pelo estranhamento e a observação participante. $\bigcirc$ estranhamento é observar aquilo que the é comum como se fosse estranho e vice-versa. Esse fato é vivenciado pela observação, o que implica uma característica importante deste tipo de pesquisa: a coleta de dados numa situação de campo. Além dessa, outra característica associada à etnografia é a descrição densa na captura da perspectiva do outro, por isso, o principal instrumento deste tipo de pesquisa é o próprio pesquisador.

Na terceira parte, André salienta as vantagens e as qualidades do pesquisador no estudo de caso. Dentre essas, tem-se a possibilidade de fornecer uma visão profunda, ampla e integrada de uma unidade social complexa, favorecendo a capacidade de retratar as situações da vida real, ser tolerante à ambiguidade, sensível e comunicativo. Porém, o pesquisador necessita de uma boa aceitação de sua presença no campo. A capacidade heurística no estudo de caso é utilizada para expandir novas experiências para o leitor, novos sentidos sobre o fenômeno estudado, contudo, pondera-se o cuidado para que o pesquisador não se exima de um posicionamento sobre a problemática.

$\bigcirc$ estudo de caso tem um potencial de contribuir para a resolução dos problemas da prática educacional por conta dos conhecimentos valiosos para medidas de natureza tanto prática como política. Tais conhecimentos devem ser pautados em princípios éticos e a necessidade do preparo do pesquisador deve revelar claramente os seus critérios de escolhas para que não afete negativamente a vida dos sujeitos ou venha comprometer o futuro da instituição ou programa pesquisado.

Na quarta parte, o livro situa a prática do estudo de caso, iniciando com a fase exploratória, típica de qualquer pesquisa qualitativa porque concebe a realidade como uma construção social, ou seja, nas interações dos sujeitos em seus ambientes é que a realidade é construída. Esta fase é o 
momento da definição da unidade de análise, das questões iniciais a serem confirmadas ou replanejadas.

A fase de delimitação e de coleta de dados acontece após a identificação dos elementos-chave do estudo. Nesta fase, o pesquisador utiliza-se de fontes variadas, instrumentos estruturados e, em se tratando do caso etnográfico, além da observação, a entrevista se revela como uma das principais técnicas de coleta, assim também como a análise de documento, pois complementa os dados das outras fontes e fornece base para a triangulação.

Na quinta parte, a autora traz a discussão da validade, fidedignidade e generalização nos estudos de caso. Inicia problematizando sobre as condições práticas de realizar pesquisa no Brasil com as demandas das atividades profissionais diárias, uma vez que este tipo de pesquisa requer uma imersão prolongada na análise dos dados para apresentação das diferentes interpretações que os sujeitos possuem sobre a mesma situação.

Ainda nesta parte, destaca as negociações entre pesquisador e pesquisado que conduzem o respeito à relevância do que será publicizado. Dessa forma, os conceitos de validade e fidedignidade são diferenciados de outros tipos de pesquisa, em especial aquelas mais conservadoras. No estudo de caso, o que se pretende apresentar é uma das possíveis versões do caso, dando margem a novas interpretações e, assim, comunicar que a versão do investigador não é a única, porém, deve apresentar elementos para que o leitor possa julgar a credibilidade do relato.

No estudo de caso etnográfico, a experiência vicária transforma-se numa fonte de generalização naturalística, ou seja, com base nas experiências apresentadas pelo pesquisador, o leitor fará relação com outros casos, generalizando seus conhecimentos.

A leitura desta obra se faz necessária para entender que o conhecimento gerado pelo estudo de caso apresenta-se mais contextualizado devido ao tempo dedicado no campo investigado. Esta obra se mostra essencial e a defesa do estudo de caso é benfazeja quando há uma situação com especificidades únicas, pois se enfatiza a particularidade do fenômeno, requerendo uma análise em profundidade. Portanto, esta obra é indicada à leitura e traz as peculiaridades do estudo de caso para a área educacional, com ênfase na etnografia. 
Ms. Francy Sousa Rabelo

Doutoranda do Programa de Pós-Graduação em Educação

Universidade Estadual do Ceará (Fortaleza)

Grupo de Pesquisa Docência no Ensino Superior e na Educação Básica

Profa. Departamento de Educação I

Universidade Federal do Maranhão (São Luis) ORCID ID: http:/ / orcid.org/0000-000 1-983 1-8874

Email: franrabelo@hotmail.com

Profa. Dra. Maria Socorro Lucena Lima Universidade Estadual do Ceará (Fortaleza) Programa de Pós-Graduação em Educação Grupo de Pesquisa Docência no Ensino Superior e na Educação Básica ORCID ID: http: / / orcid.org/0000-000 1-6600-1 164 Email: socorro_lucena@uol.com.br

Recebido 22 jul. 2019 Aceito 12 ago. 2019 